\title{
Tratamento de Água de abASTECIMENTO POR MEIO DA TECNOLOGIA DE FILTRAÇÃO EM MÚLTIPLAS ETAPAS - FIME
}

\author{
WATER TREATMENT BY MULTISTAGE FILTRATION SYSTEMS - MSF
}

\author{
LUCIANA RODRIGUES VALADARES VERAS
}

Engenheira Civil. Doutora em Hidráulica e Saneamento pela Escola de Engenharia de São Carlos - USP

\section{LUIZ DI BERNARDO}

Professor Titular do Departamento de Hidráulica e Saneamento da Escola de Engenharia de São Carlos - USP

\section{Recebido:28/11/06 Aceito: 07/03/08}

\section{RESUMO}

A pesquisa apresenta uma avaliação do sistema de Filtração em Múltiplas Etapas (FiME), utilizando instalação piloto composta por duas unidades de pré-filtros dinâmicos em série, três linhas de pré-filtros de escoamento ascendente, em série e em camadas, e quatro filtros lentos com diferentes meios filtrantes. $\mathrm{O}$ desempenho do sistema foi avaliado através de parâmetros como turbidez, cor aparente, sólidos suspensos, coliformes totais e fecais e ferro. Os resultados mostraram que as três linhas de pré-filtros de escoamento ascendente apresentaram comportamento semelhante em todas as carreiras de filtração. Os quatro filtros lentos tiveram igual desempenho com relação a sólidos suspensos e os filtros lentos 3 e 4 alcançaram as maiores remoções de ferro, turbidez e cor em algumas carreiras de filtração.

PALAVRAS-CHAVE: FiME, filtração lenta, filtração em múltiplas etapas, pré-filtros dinâmicos, filtros lentos.

\begin{abstract}
This work presents an evaluation of some alternatives of multistage filtration system (MSF), using a pilot plant comprising two dynamic roughing filters, in series, three lines of upflow roughing filters, linked in series and in layers and four slow sand filters with different granular media composition. The performance of the system was evaluated by monitoring some water quality parameters such as: turbidity, suspended solids, total coliforms, fecal coliforms and particle size. The results showed that the MSF system produced effluents with low turbidity, solids and coliforms. The three lines of upflow roughing filters indicated the same efficiency in all tests. The four slow sand filters had similar performance concerning solids reductions and the slow sand filters 3 and 4 reached the greatest reductions in iron, organic matter, turbidity and color, in some experiments.
\end{abstract}

KEYWORDS: Multistage filtration system, slow sand filters, dynamic roughing filter, slow sand filtrations.

\section{INTRODUÇÃO}

Nos últimos anos tem-se agravado continuamente os problemas relacionados à poluição dos mananciais, principalmente em decorrência do desenvolvimento agrícola e industrial, exigindo medidas tecnológicas apropriadas ao tratamento da água destinada ao consumo humano. A disponibilidade de recursos financeiros em países em desenvolvimento é restrita e por isso, o estudo de alternativas de tecnologias econômicas passa a ser uma necessidade ao equacionamento da questão do saneamento no país.

A Filtração em Múltiplas Etapas, FiME, é um sistema de simples construção, com instalações de baixo custo, nas quais a instrumentação pode ser praticamente eliminada. Além disso, é uma tecnologia adequada às zonas rurais e pequenos e médios municípios. Segundo Visscher (1996), quando devidamente selecionada, projetada, construída e operada, a FiME produz água filtrada com baixa turbidez, sem a presença de impurezas nocivas e livre de organismos patogênicos.

De acordo com Galvis et al (1998) a filtração em múltiplas barreiras é conveniente por retirar primeiro o material maior e mais pesado, e gradualmente separar e inativar impurezas menores, como material coloidal e microrganismos.

A água deve passar por um tratamento de várias etapas, principalmente se contiver impurezas de tamanhos variados. Para águas superficiais, o processo deve conter pelo menos duas etapas. $\mathrm{Na}$ primeira delas, conhecida como pré-tratamento, dá-se a separação de sólidos grosseiros por meio de filtros de areia grossa ou pedregulho. Em seguida, tem-se a remoção de partículas finas e microrganismos remanescentes, onde a filtração lenta e a cloração são os processos comumente utilizados. Desta forma, as impurezas são colocadas frente a um tratamento de múltiplas barreiras

No tratamento sem coagulação química, a filtração lenta e a cloração são os principais processos capazes de assegurar a produção de água com qualidade adequada ao consumo humano. Porém, a eficiência da filtração lenta pode ser comprometida, se a turbidez da água bruta for superior a $10 \mathrm{uT}$. Neste caso, a pré-filtração possibilita a redução das impurezas da água antes de filtração lenta.

Esta estação de tratamento sem coagulação química pode ser constituída de pré-filtro dinâmico, pré-filtro de pedregulho com escoamento ascendente ou descendente, pré-filtro com escoamento horizontal e filtros lentos. Por razões operacionais, são previstas pelo menos duas unidades de pré-filtros, operando em paralelo para evitar 
a suspensão desta etapa de tratamento durante o tempo necessário para limpeza e manutenção.

Os pré-filtros dinâmicos são instalações destinadas a reduzir a quantidade de sólidos suspensos, minimizando assim, os problemas de operação e manutenção nas unidades subsequentes do sistema de tratamento. Devido à capacidade de reagir frente a crescentes cargas de sólidos, deu-se o nome de "dinâmico" a esse tipo de pré-filtro. Eles funcionam continuamente com vazão de água bruta, sendo parte dela filtrada e a restante escoada sobre a camada superior de pedregulho. $\mathrm{O}$ contínuo depósito de impurezas no meio filtrante causa o aumento da resistência hidráulica e a diminuição da taxa de filtração. Quando isso ocorre, é necessário raspar o lodo da superfície de pedregulho e abrir o sistema de drenagem para que o funcionamento se restabeleça.

Os pré-filtros de escoamento ascendente são divididos em dois grupos: aqueles compartimentados em duas, três ou quatro unidades em série, cada uma com granulometria específica, e os que têm material granular com tamanho variado, disposto numa única unidade. Na pré-filtração em série, a água filtrada no primeiro compartimento é encaminhada para a segunda câmara, de menor granulometria, e assim sucessivamente. Nos pré-filtros em camadas, o material é disposto em sub-camadas de pedregulho decrescente no sentido do escoamento. Essas unidades são geralmente operadas com taxas de filtração entre 12 e $48 \mathrm{~m}^{3} / \mathrm{m}^{2}$ dia. Estudos realizados por diversos autores demonstram remoções de turbidez da ordem de 60 a $85 \%$, de cor entre 10 e $35 \%$ e de coliformes totais entre 67 e 90\% (Ochieng et al, 2004; Clarke et al, 2004; PROSAB, 1999).

Os filtros lentos trabalham com taxas de filtração entre 3 a $6 \mathrm{~m}^{3} / \mathrm{m}^{2}$ dia e utilizam areia de granulometria mais fina, normalmente com grãos de tamanho entre 0,15 e $1,00 \mathrm{~mm}$. No início da carreira de filtração, a altura d'água sobre o leito é mínima, crescendo gradualmente para compensar a resistência hidráulica devido à retenção de impurezas e da formação da membrana biológica (schmutzdecke). Quando o nível d'água atinge a altura máxima permitida, o filtro é retirado de operação para limpeza, que consiste na raspagem de 1 a $3 \mathrm{~cm}$ da camada superior do leito filtrante. A areia raspada é carreada para fora dos filtros, onde é lavada, seca, homogeneizada e guardada para reposição futura. As instalações devem operar continuamente, sem interrupções, pois as várias populações bacterianas existentes estão adaptadas ao tipo e quantidade de alimento fornecido por aquela determinada vazão. Uma súbita mudança na taxa de filtração tende a perturbar o equilíbrio no topo da areia, resultando na deterioração da qualidade do efluente.

A necessidade de se encontrar uma técnica que facilitasse a limpeza dos filtros lentos e que possibilitasse o aumento na duração da carreira ou aumento de taxa de filtração, levou alguns pesquisadores a estudarem a utilização de mantas sintéticas no topo da camada de areia (PROSAB, 1999)

Alguns pesquisadores (Bauer et al (1996) e Page et al (1996) estudaram as vantagens da filtração lenta combinada com o uso do carvão ativado granular. Essa tecnologia, denominada "CAG sanduiche", tem alcançado consideráveis remoçóes de compostos orgânicos, diminuindo a cor, sabor e odor da água, além de reduzir os subprodutos da desinfecção (THMs) e controlar o nível de micropoluentes (pesticidas).

Com o desenvolvimento cada vez maior de alternativas de pré-tratamento, a FiME é uma opção de tecnologia que pode superar as limitações da filtração lenta, operando adequadamente como uma única etapa de tratamento, antes da desinfecção.

O presente trabalho investigou a utilização da Filtração em Múltiplas Etapas, composta de dois pré-filtros dinâmicos, pré-filtros de escoamento ascendente em série e em camadas e filtros lentos com diferentes meios filtrantes, possibilitando a análise de diversos parâmetros importantes na elaboração de projetos e na aplicação dessa tecnologia para diferentes comunidades.

\section{METODOLOGIA}

A instalação piloto foi montada nas dependências da Estação de Tratamento de Água de São Carlos - SP. A água bruta, armazenada em um reservatório de 500 litros, seguia por bombeamento para uma caixa de distribuição composta de vertedor (caixa 1), onde era feito o controle da vazão afluente aos filtros. A Figura 1 mostra o esquema geral da instalação piloto.
A água seguia então para duas unidades de pré-filtro dinâmico de pedregulho (PFD1 e PFD2), em série.

A distribuição de vazões às linhas 1,2 e 3, de pré-filtros verticais de escoamento ascendente (PFVA) era realizada através de uma caixa com vertedor (caixa 2), composta de três saídas, com registros, para a obtenção da vazão desejada em cada linha.

A linha 1 era constituída de quatro pré-filtros de escoamento ascendente (PFVA1, PFVA2, PFVA3 e PFVA4), instalados em série; a segunda, de dois (PFVA12 e PFVA34) e a terceira de um único pré-filtro em camadas (PFVA 1234).

As três linhas eram interligadas a uma terceira caixa de distribuição (caixa 3), com quatro vertedores, que alimentavam os filtros lentos (FL1, FL2, FL3, FL4). Nesses filtros foram investigadas combinaçôes de alturas de camadas de areia, com e sem a utilização de mantas sintéticas não tecidas, além de carvão granular.

As treze unidades constituintes do sistema foram construídas em chapa metálica, sendo onze de seção circular (pré-filtros verticais ascendentes e filtros lentos), com diâmetro interno igual a $0,80 \mathrm{~m}$ e área de $0,5 \mathrm{~m}^{2} \mathrm{e}$ dois retangulares (PFD1 e PFD 2) com áreas iguais a $1,125 \mathrm{~m}^{2}(0,75 \mathrm{~m} \times 1,50 \mathrm{~m})$.

As respectivas vazões foram distribuídas aos filtros em tubulações de PVC com diâmetro nominal de $50 \mathrm{~mm}$ (nos pré-filtros) e $20 \mathrm{~mm}$ (nos filtros lentos), por gravidade. $\mathrm{Na}$ extremidade do tubo de alimentação de cada filtro lento foi colocada uma placa defletora, permitindo uma distribuição mais uniforme da vazão afluente. A Figura 1 mostra o esquema da instalação piloto montada na ETA em São Carlos - SP.

As características do meio granular de cada unidade são mostradas nas Tabelas 1 e 2 .

As especificações técnicas referentes às mantas M1 (branca) e M2 (preta) estão apresentadas na Tabela 3.

Os ensaios foram realizados para diferentes taxas de filtração, conforme mostrado na Tabela 4. Os dados foram submetidos a tratamento estatístico.

A limpeza dos pré-filtros dinâmicos era realizada mediante revolvimento do topo do meio granular, com o auxílio de um rastelo, para liberar as impurezas ali contidas. Após esse procedimento abria-se a descarga para remoção dos sólidos retidos no pedregulho mais 


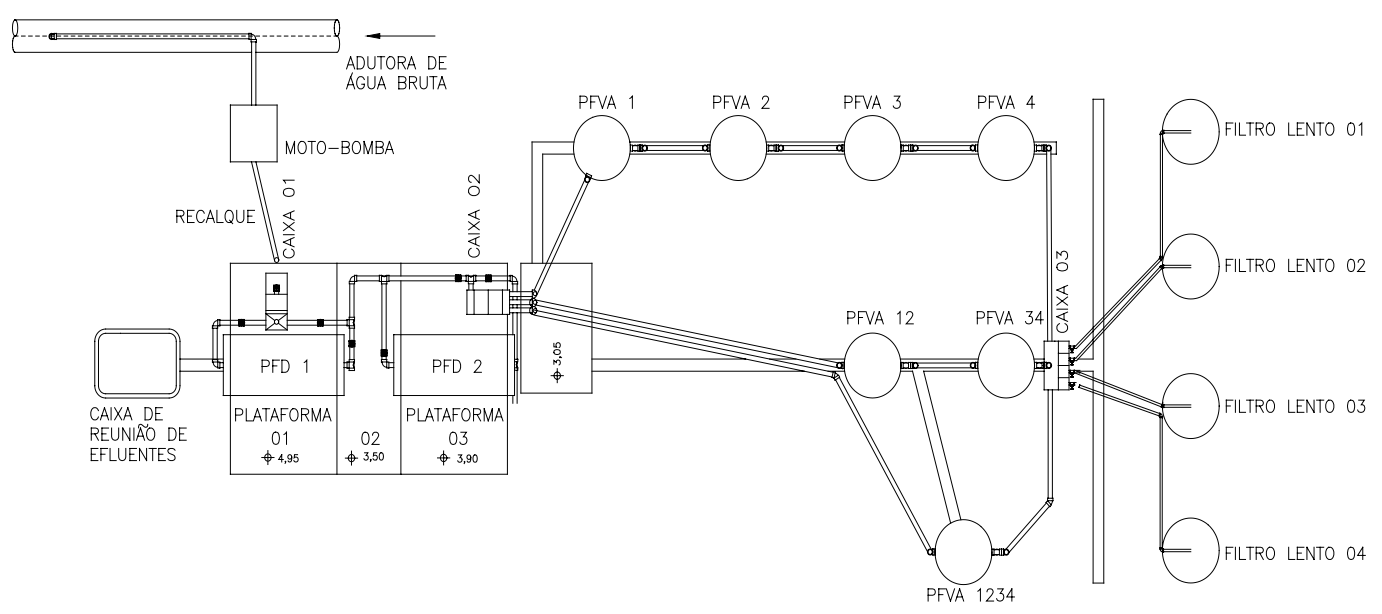

Figura I - Esquema da instalação piloto

Tabela I - Meios filtrantes - pré-filtros dinâmicos (PFDs) e pré-filtros verticais ascendentes (PFVAs)

\begin{tabular}{ccc}
\hline Unidades & $\begin{array}{c}\text { Tamanho } \\
(\mathrm{mm})\end{array}$ & $\begin{array}{c}\text { espessura da camada } \\
(\mathrm{mm})\end{array}$ \\
\hline PFD 1 & $15,9-25,4$ & 0,4 \\
& $12,7-19,0$ & 0,25 \\
& $6,4-12,7$ & 0,25 \\
PFD 2 & $19,0-25,4$ & 0,4 \\
& $9,6-15,9$ & 0,25 \\
PFVA 1 & $4,8-9,6$ & 0,25 \\
& $31,4-50$ & 0,2 \\
PFVA 2 & $19,0-25,4$ & 0,4 \\
& $31,4-50$ & 0,2 \\
PFVA 3 & $9,6-15,9$ & 0,4 \\
& $19,0-31,4$ & 0,2 \\
PFVA 4 & $3,2-6,4$ & 0,4 \\
& $9,6-15,9$ & 0,2 \\
PFVA 12 & $1,41-3,2$ & 0,4 \\
& $50-75$ & 0,25 \\
& $19,0-25,4$ & 0,4 \\
PFVA 34 & $9,6-15,9$ & 0,4 \\
& $31,4-50$ & 0,25 \\
& $3,2-6,4$ & 0,4 \\
PFVA 1234 & $1,41-3,2$ & 0,4 \\
& $31,4-50$ & 0,5 \\
& $19,0-25,4$ & 0,4 \\
& $9,6-15,9$ & 0,4 \\
& $3,2-6,4$ & 0,4 \\
& $1,41-3,2$ & 0,4 \\
\hline
\end{tabular}


Tabela 2 - Meios filtrantes - filtros lentos (FLs)

\begin{tabular}{|c|c|c|}
\hline Unidades & $\begin{array}{c}\text { Tamanho } \\
(\mathrm{mm})\end{array}$ & $\begin{array}{c}\text { espessura da camada } \\
(\mathrm{mm})\end{array}$ \\
\hline \multirow[t]{6}{*}{ FL 1} & $31,4-50,0$ & 0,30 \\
\hline & $15,9-25,4$ & 0,15 \\
\hline & $7,9-12,7$ & 0,10 \\
\hline & $6,4-3,2$ & 0,10 \\
\hline & $1,41-2,4$ & 0,10 \\
\hline & $0,08-1,0$ & 0,70 \\
\hline \multirow{6}{*}{$\begin{array}{c}\text { FL } 2 \\
\text { (uso de } 2 \text { mantas } \\
\text { Acima da camada } \\
\text { de areia) }\end{array}$} & $31,4-50,0$ & 0,30 \\
\hline & $15,9-25,4$ & 0,15 \\
\hline & $7,9-12,7$ & 0,10 \\
\hline & $6,4-3,2$ & 0,10 \\
\hline & $1,41-2,4$ & 0,10 \\
\hline & $0,08-1,0$ & 0,40 \\
\hline \multirow{6}{*}{$\begin{array}{l}\text { FL } 3 \\
\text { (uso de } 30 \mathrm{~cm} \text { de } \\
\text { CAG no meio da } \\
\text { camada de areia) }\end{array}$} & $31,4-50,0$ & 0,30 \\
\hline & $15,9-25,4$ & 0,15 \\
\hline & $7,9-12,7$ & 0,10 \\
\hline & $6,4-3,2$ & 0,10 \\
\hline & $1,41-2,4$ & 0,10 \\
\hline & $0,08-1,0$ & 0,55 \\
\hline \multirow{6}{*}{$\begin{array}{c}\text { FL } 4 \\
\text { (uso de } 30 \mathrm{~cm} \text { de } \\
\text { CAG no meio da } \\
\text { camada de areia e } \\
2 \text { mantas) }\end{array}$} & $31,4-50,0$ & 0,30 \\
\hline & $15,9-25,4$ & 0,15 \\
\hline & $7,9-12,7$ & 0,1 \\
\hline & $6,4-3,2$ & 0,1 \\
\hline & $1,41-2,4$ & 0,1 \\
\hline & $0,08-1,0$ & 0,40 \\
\hline
\end{tabular}

Tabela 3 - Características das mantas utilizadas nos filtros lentos

\begin{tabular}{cccc}
\hline Propriedades & Unidade & M1 & M2 \\
\hline Massa específica média do fio & $\mathrm{g} / \mathrm{m}^{3}$ & 1,1215 & 0,9835 \\
Massa específica média da manta & $\mathrm{g} / \mathrm{m}^{3}$ & 0,1713 & 0,1151 \\
Condutividade hidráulica K & $\mathrm{mm} / \mathrm{s}$ & 1,31 & 7,16 \\
Porosidade E & $\%$ & 84,72 & 88,29 \\
Diâmetro médio do fio & $\mu \mathrm{m}$ & 29,58 & 45,09 \\
Superfície específica $\mathrm{S}_{0}$ & $\mathrm{~m}^{2} / \mathrm{m}^{3}$ & 20662 & 10388 \\
\hline
\end{tabular}


Tabela 4 - Taxas de filtração empregadas nas unidades

\begin{tabular}{ccccc}
\hline $\begin{array}{c}\text { Carreiras de } \\
\text { filtraçao }\end{array}$ & $\begin{array}{c}\text { Taxas no } \\
\text { PFD1 } \\
\text { m/dia }\end{array}$ & $\begin{array}{c}\text { Taxas no } \\
\text { PFD2 } \\
\text { m/dia }\end{array}$ & $\begin{array}{c}\text { Taxas nos } \\
\text { PFVAs } \\
\text { m/dia }\end{array}$ & $\begin{array}{c}\text { Taxas nos } \\
\text { FLs } \\
\text { m/dia }\end{array}$ \\
\hline 1A & 48 & 36 & 12 & 4 \\
1B & 48 & 36 & 12 & 4 \\
2A & 36 & 24 & 8 & 3 \\
2B & 36 & 24 & 8 & 3 \\
3A & 60 & 48 & 16 & 3 \\
3B & 60 & 48 & 16 & 3 \\
4A & 48 & 36 & 12 & 6 \\
$4 B$ & 48 & 36 & 12 & 6 \\
\hline
\end{tabular}

grosso e nos drenos. O efluente dos pré-filtros ascendentes era coletado por meio de tubos de $50 \mathrm{~mm}$, com 11 orifícios de 6,4 mm (Figura 2). Para limpeza das unidades foram realizadas descargas de fundo no final de cada carreira (Figura 3).

Nos filtros lentos, a carreira de filtração era iniciada com a introdução de água no sentido ascendente, através da tubulação de saída. Essa operação foi realizada lentamente, com taxa de $1 \mathrm{~m}^{3} / \mathrm{m}^{2}$ dia para evitar a estratificação do meio filtrante, até que o nível d'água cobrisse a areia. Após esse procedimento, calibrava-se a vazão afluente, permitindo-se o início de operação do filtro.

A carreira de filtração era considerada encerrada quando a perda de carga atingia $1,0 \mathrm{~m}$, momento em que o filtro era retirado de operação para lavagem. Assim, abria-se a válvula de descarga, para que o nível de água ficasse abaixo do topo da areia. A limpeza dos filtros lentos 1 e 3 (sem manta) se dava através da raspagem manual de aproximadamente $1 \mathrm{~cm}$ do topo da areia e posterior lavagem da mesma, com água corrente e agitação manual. Após a lavagem, o leito filtrante era armazenado para ser recolocado, caso fosse necessário.

Nos filtros lentos contendo mantas (FL2 e FL4), o procedimento de limpeza se dava através da lavagem da mesma com o auxílio de mangueira de alta pressão. Terminada essa etapa, as mantas eram recolocadas nos filtros.

Com o objetivo de evitar o crescimento de algas no sobrenadante, o topo de cada filtro foi coberto com lona plástica.

A avaliação da eficiência das unidades de pré-filtração e de filtração

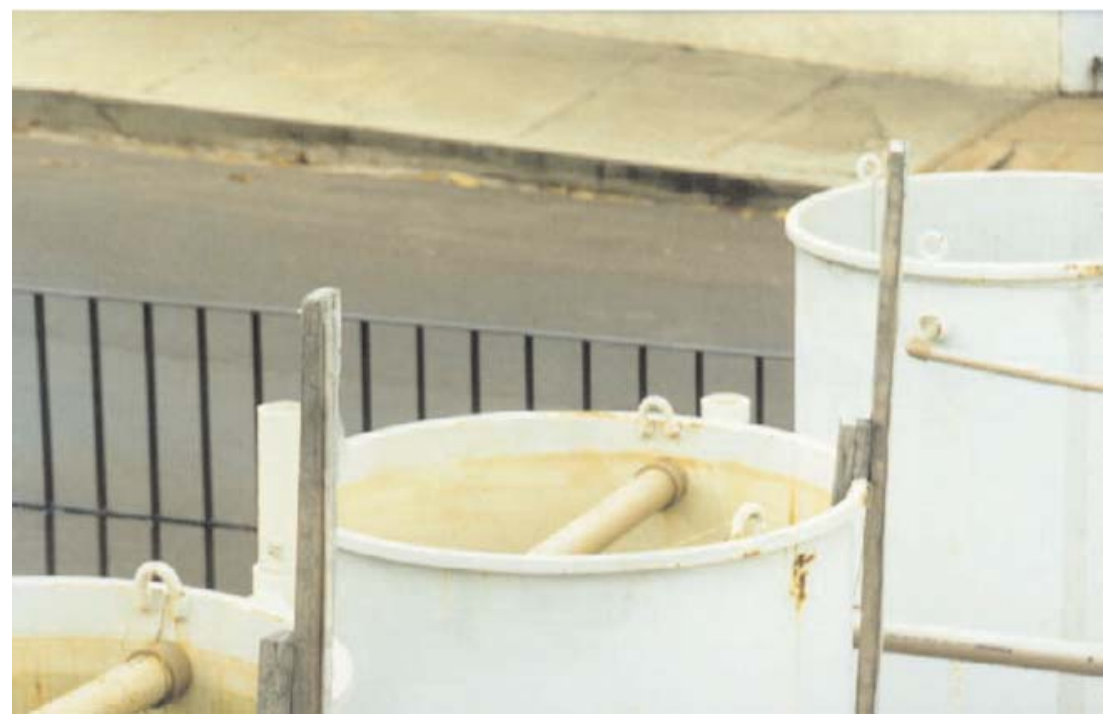

Figura 2 - Detalhe do tubo de coleta nos pré-filtros verticais de escoamento ascendente

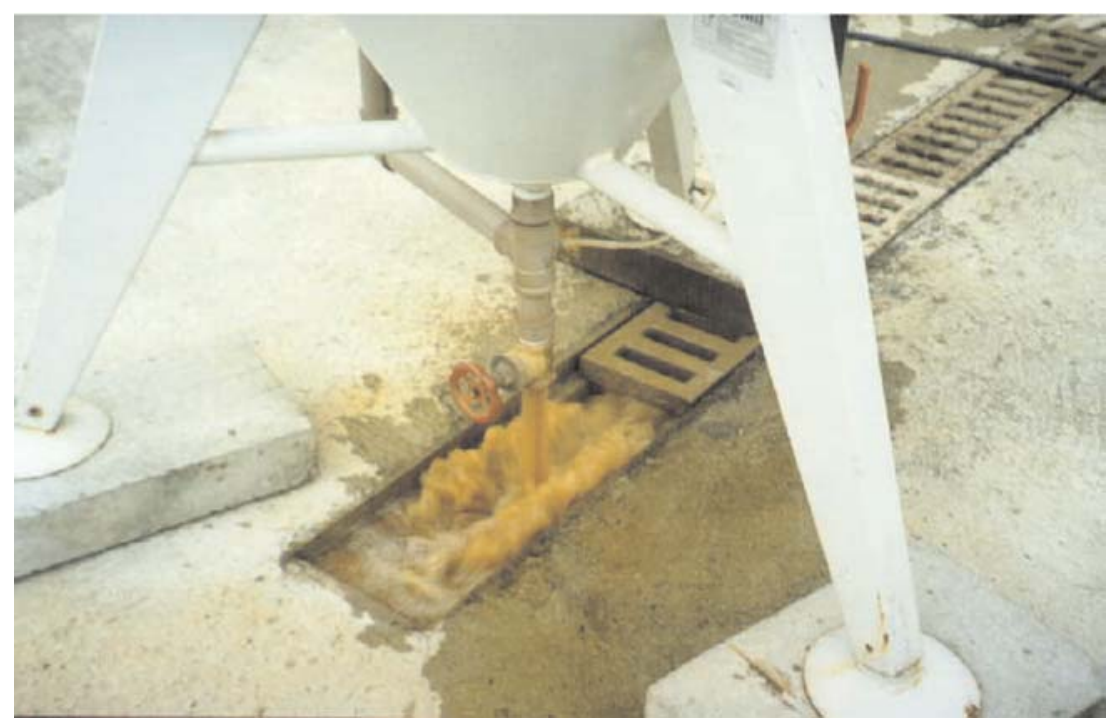

Figura 3 - Descarga de fundo do pré-filtro vertical de escoamento ascendente (PFVA I 234) 
lenta foi realizada pelo monitoramento de características físicas, químicas e bacteriológicas nos afluentes e efluentes das unidades, com frequência de amostragem apresentada na Tabela 5. Além desses parâmetros, foram monitoradas as taxas de filtração através de vertedores e a perda de carga nos meios filtrantes, de cada unidade, com a utilização de piezômetros.

\section{RESULTADOS E DISCUSSÕES}

Em algumas carreiras de filtração, a água bruta apresentou picos elevados de turbidez, que chegaram a $335 \mathrm{uT}$ e 264 uT (Figuras 4, 5 e 6). Esse fato refletiu de maneira significativa em todas as unidades do sistema. Nesses casos, os PFD 1 e 2 alcançaram eficiências máximas de remoção de turbidez de $63 \%$ e $37 \%$, respectivamente. No restante das carreiras, quando a turbidez da água bruta sofreu poucas variações, os percentuais de remoção nesses préfiltros estiveram em torno de 35\%. As eficiências de remoção de cor aparente nos pré-filtros dinâmicos 1 (PFD 1) e 2 (PFD 2) foram iguais a $53 \%$ e $13 \%$ na carreira $1 \mathrm{~B}$ e a $39 \%$ e $30 \%$ na carreira 2A. Nos demais ensaios, os percentuais de remoção no PFD 1 estiveram entre 25 e $29 \%$ e no PFD 2, entre 23 e $30 \%$. A eficiência de remoção média de sólidos suspensos totais no pré-filtro dinâmico 1 variou entre 22 e $66 \%$. No pré-filtro dinâmico 2 a média percentual de retenção ficou entre 9 a $30 \%$. Os PFD 1 e 2 proporcionaram remoções médias de coliformes totais de até 67,6 e $40 \%$ respectivamente. Com relação a coliformes fecais, as remoções atingiram 41 e $62 \%$, respectivamente. O teor de ferro na água bruta variou entre 2,93 a $0,90 \mathrm{mg} / \mathrm{L}$. Os ensaios apontaram uma tendência de aumento da remoção no decorrer das carreiras, nesses pré-filtros, os quais obtiveram reduçôes máximas de 15 e $12 \%$, respectivamente.

Os testes estatísticos indicaram que não houve diferença significativa entre as três linhas de pré-filtros de escoamento ascendente com relação à remoção de turbidez, cor aparente, ferro, coliformes totais e fecais. Assim, pode-se dizer que esses pré-filtros, em série e em camadas, apresentaram comportamento semelhante, quando foram utilizadas taxas iguais a 8, 12 e $16 \mathrm{~m} /$ dia (Figura 7). A eficiência de remoção nas linhas alcançou $81 \%$
Tabela 5 - Principais parâmetros físico-químicos e bacteriológicos de controle e frequências de amostragem

\begin{tabular}{cc}
\hline Parâmetro & Freqüência \\
\hline Turbidez & $2 \times$ dia \\
Cor aparente & $2 \times$ dia \\
Temperatura & $2 \times$ dia \\
pH & $2 \times$ dia \\
Sólidos suspensos & $2 \times$ semana \\
Ferro & $1 \times$ semana \\
Coliformes totais e fecais $/ 100 \mathrm{ml}$ & $1 \times$ semana \\
\hline
\end{tabular}

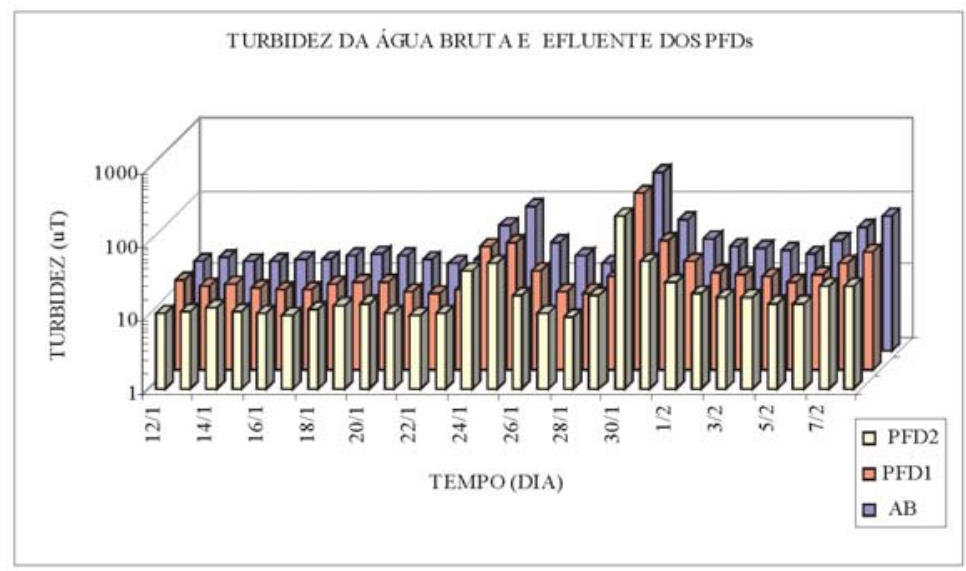

Figura 4 - Turbidez (UT) efluente dos PFDs - carreira IB

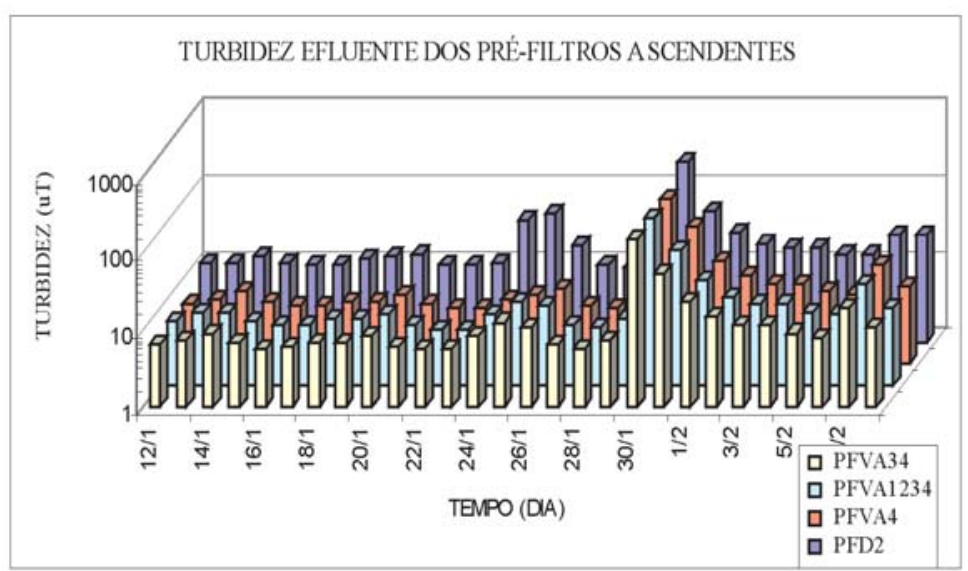

Figura 5 - Turbidez (uT) efluente dos PFVAs - carreira IB 
para turbidez, 54\% para cor aparente, $44 \%$ para ferro e $93 \%$ para coliformes totais e fecais. Não ocorreu diferença na remoção de sólidos suspensos totais entre as três linhas de pré-filtros de escoamento ascendente, quando foram utilizadas taxas iguais a 3 e $4 \mathrm{~m} / \mathrm{dia}$. A linha 3, composta por um pré-filtro em camadas, pareceu ser mais eficiente com o emprego de taxa igual a $6 \mathrm{~m} /$ dia para sólidos suspensos. As taxas de remoção ficaram entre $48 \%$ e $74 \%$ para estes pré-filtros.

As análises estatísticas detectaram diferença na remoção de turbidez, cor aparente e ferro para os filtros lentos, na maioria dos ensaios. De maneira geral, os FL 3 e FL 4 obtiveram melhores resultados em relação aos FL 1 e 2 (Figuras 8 e 9). Com relação à remoção de sólidos suspensos totais, pode-se afirmar que estatisticamente os quatro filtros lentos não apresentaram diferenças na redução desse parâmetro. Esse resultado permite concluir que o uso de mantas e de carvão ativado granular não interferiu na retenção de sólidos (figura 10). As remoçōes médias variaram entre 40 e $80 \%$.

A filtração lenta demonstrou grande contribuição na redução do teor de ferro, com médias de remoção de até $92,7 \%$.

Os resultados estatísticos indicaram diferença nos tratamentos somente nas duas primeiras carreiras, com relação à coliformes totais e fecais. Os FL 3 e 4 apresentaram melhor performance nessas carreiras, sugerindo uma contribuição do carvão ativado granular presente nesses filtros. A remoção ao final da filtração lenta alcançou percentuais médios acima de 99\%. Algumas análises apontaram coliformes fecais igual a zero, principalmente a partir da carreira 2A. A eficiência global do sistema chegou a $96 \%$ em períodos de pico para cor aparente e a $98,6 \%$ para turbidez.

\section{CONCLUSÕES}

Os resultados obtidos neste trabalho conduziram às seguintes conclusões:

1) o pré-filtro dinâmico 1 , com maior granulometria, demonstrou maior capacidade de absorver picos de turbidez do que o pré-filtro dinâmico 2;

2) não houve diferença estatística entre o desempenho das três linhas de

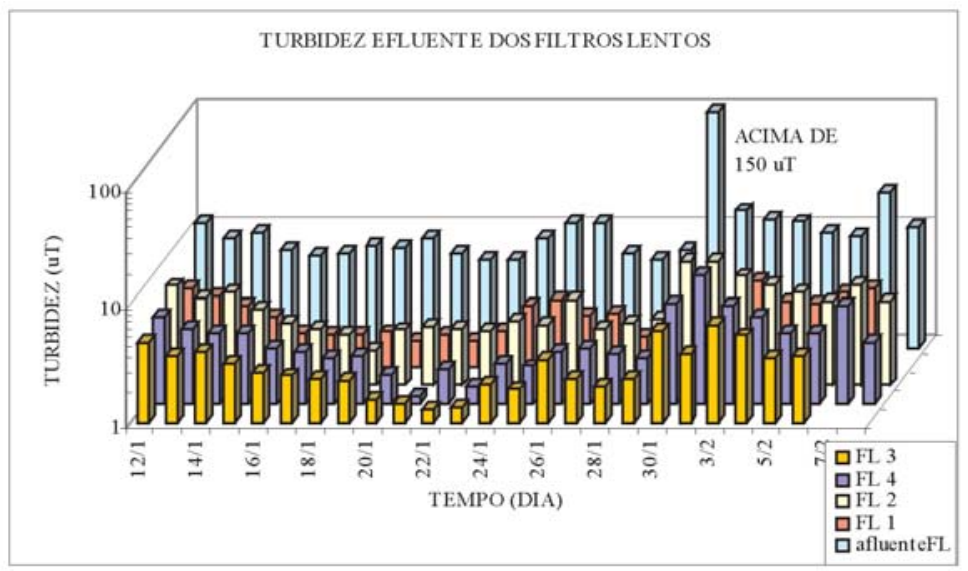

Figura 6 - Turbidez (UT) efluente dos PLs - carreira IB

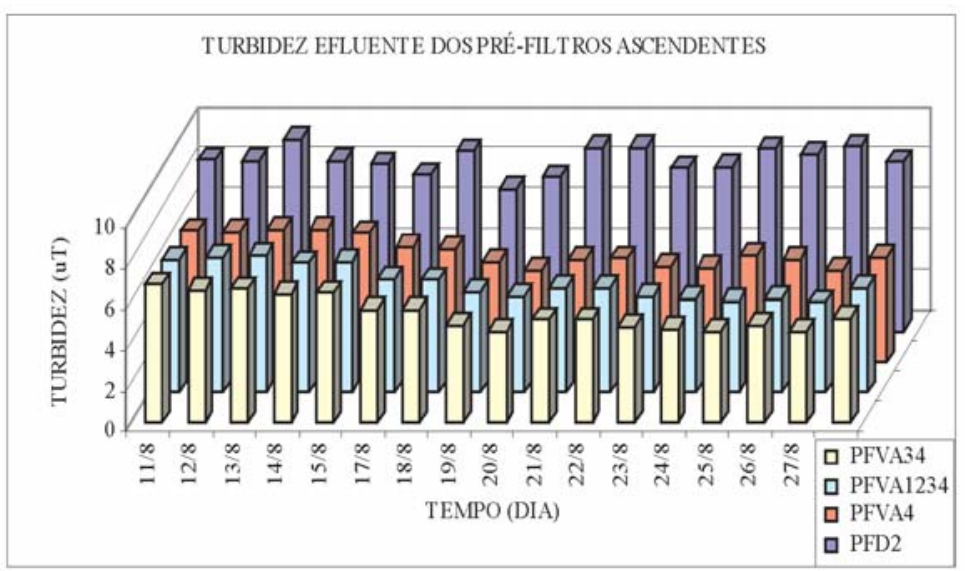

Figura 7 - Turbidez (UT) afluente e efluente dos PFVAs - carreira 4A

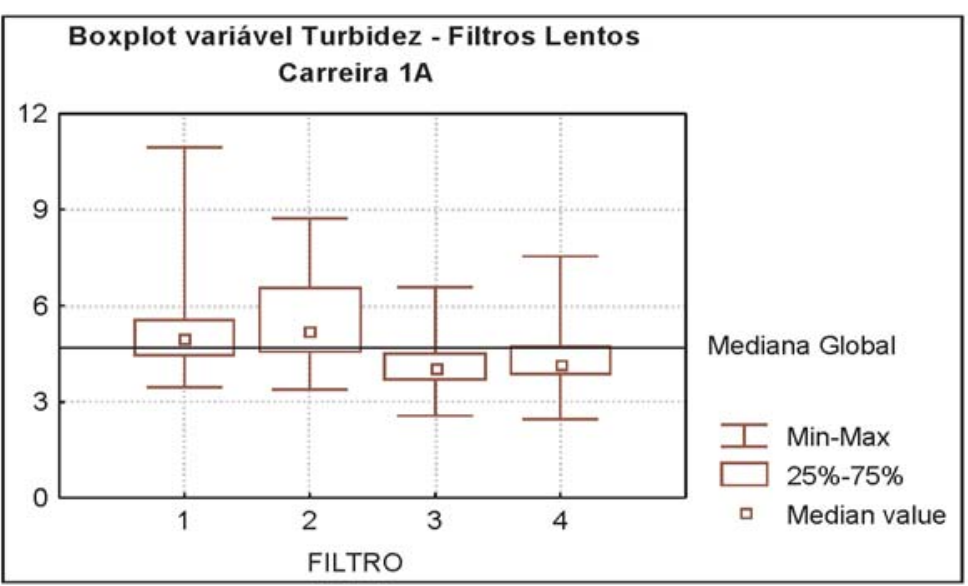

Figura 8 - Turbidez (UT) efluente dos FLs - carreira IA 


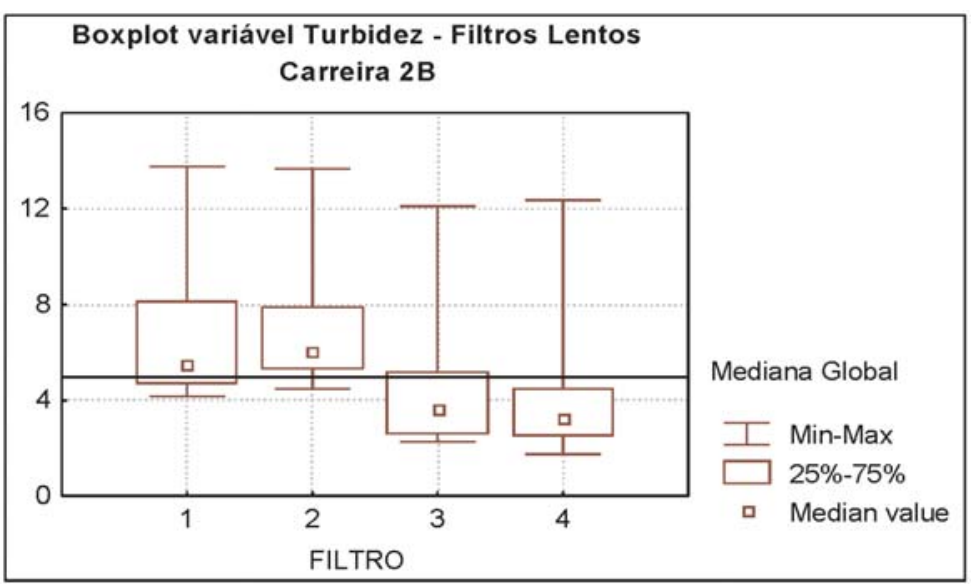

Figura 9 - Turbidez (uT) efluente dos FLs - carreira 2B

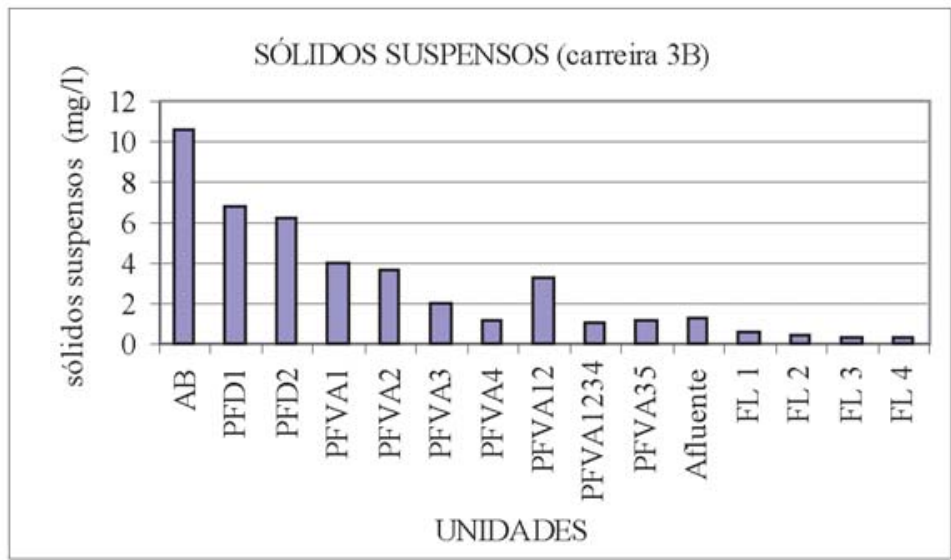

Figura 10 - Sólidos suspensos (mg/L) - carreira 3B

pré-filtros de escoamento ascendente com relação aos parâmetros analisados;

3) a redução de sólidos suspensos foi estatisticamente igual para os quatro filtros lentos, em todas as carreiras de filtração, sendo possível afirmar que o uso de mantas e de carvão ativado granular não interferiu na eficiência desses filtros;

4) os filtros lentos 3 e 4 apresentaram melhor desempenho na remoção dos contaminantes monitorados.

Com base nas conclusões acima pode-se dizer que os seguintes sistemas FIME foram considerados como as melhores alternativas por apresentarem maior desempenho durante o desenvolvimento da pesquisa:

1) pré-filtro dinâmico 1 seguido ou não do pré-filtro dinâmico 2 , dependendo da qualidade da água bruta. Em casos de rios onde ocorram picos de turbidez com grande freqüência, pode ser recomendável a utilização de duas unidades de pré-filtro dinâmico. de Abastecimento Por Filtração Em Múltiplas Etapas. ABES. Rio de Janeiro, 1999.

PAGE, T.G. NOM Removals by "GAC Sandwich" Modification to Slow Filtration. John Wiley \& Sons, England, april, 1996.

VISSCHER, J.T., GALVIS, G.; LATORRE, J. Filtracion em multiplas etapas - FIME: bondades e limitaciones. Anais da Conferência Internacional Mejoramiento de la Calidad del água, Santiago de Cali, abril, Colômbia, 1996.

Endereço para correspondência:

Luciana Rodrigues Valadares Veras Rua Montesquieu, I05 apto 20 I Jd. Vila Mariana 04 I I 6- I 90 São Paulo - SP - Brasil Tel.: : (I I) 5083-7430 casalrodrigues@terra.com.br
2) linha 1, 2 ou 3 de pré-filtros de escoamento ascendente.

3) filtro lento 3 ou 4.

\section{REFERÊNCIAS}

BAUER, M.J. et al. GAC Enhanced Slow Sand Filtration (GAC Sandwich) In: GRAHAM, N; COLLINS, R. Advances in Slow Sand and Alternative Biological Filtration. John Wiley \& Sons, cap. 4, p.223-232, 1996.

CLARKE, B. A. et al. Multistage filtration system for developing world surface water treatment. Water Management, vol. 157, nº 3, p. 143-149 Telford, London, 2004.

GALVIS, G. et al. Filtração em Múltiplas Etapas para Tratamento de Água de Abastecimento IN: VIII SIMPÓSIO LUSO-BRASILEIRO DE ENGENHARIA SANITÁRIA E AMBIENTAL, vol 1, p. 11-27, João Pessoa - Paraíba, Brasil, 1998.

OCHIENG, G. M. M. et al. Performance of Multistage filtration using different filter media against convencional water treatment systems. Water Research Commission, vol. 30, n 3, p. 361-367, Pretoria, South Africa, 2004.

PROSAB - PROGRAMA DE PESQUISA EM SANEAMENTO BÁSICO. Tratamento de Águas 